\title{
A new species of the genus Anteon Jurine (Hymenoptera, Dryinidae) from Laos
}

\author{
Massimo Olmi', Zai-fu Xu², Adalgisa Guglielmino ${ }^{3}$, Stefano Speranza ${ }^{3}$ \\ I Tropical Entomology Research Center, Viterbo, Italy 2 Department of Entomology, South China Agricultural \\ University, Guangzhou, Guangdong, P.R. China 3 Department of Agriculture and Forestry Sciences (DAFNE), \\ University of Tuscia, Viterbo, Italy \\ Corresponding author: MassimoOlmi (olmi@unitus.it)
}

Academic editor: M. Engel | Received 5 December 2015 | Accepted 4 January 2016 | Published 8 February 2016

http://zoobank.org/8446A28C-D48A-45CB-AA2E-C2746A341E3A

Citation: Olmi M, Xu Z, Guglielmino A, Speranza S (2016) A new species of the genus Anteon Jurine (Hymenoptera, Dryinidae) from Laos. ZooKeys 561: 31-38. doi: 10.3897/zookeys.561.7417

\begin{abstract}
A new species of Anteon Jurine, 1807 is described from Laos, Houaphanh Province: A. holzschuhi sp. n. Morphologically the new species is similar to A. semipolitum Olmi, 2008, but it is distinguished by the sculpture of the face partly reticulate rugose and partly with deep punctures similar to areolae; in $A$. semipolitum the face is completely punctate and unsculptured among punctures. In addition, in the new species the distance from the outer edge of a lateral ocellus to the compound eye (OOL) is about 3.3 times as long as the distance between the inner edges of a lateral ocellus and the median ocellus (OL); in A. semipolitum OOL is less than twice as long as OL. Published identification keys to the Oriental species of Anteon are modified to include the new species.
\end{abstract}

\section{Keywords}

Taxonomy, Anteon holzschuhi, Oriental region, key, Houaphanh Province, Anteoninae

\section{Introduction}

Dryinidae (Hymenoptera, Chrysidoidea) are parasitoids of leafhoppers, planthoppers and treehoppers (Hemiptera, Auchenorrhyncha) (Carcupino et al. 1998; Guglielmino and Bückle 2003, 2010; Guglielmino et al. 2006, 2013, 2015; Guglielmino and Virla 
1998). Anteon Jurine, 1807 is a genus that is present in all zoogeographical regions (Olmi 1984; Xu et al. 2013; Olmi and Virla 2014; Olmi and Xu 2015). In total 423 species have been described from all continents (Olmi and Xu 2015) and the genus was revised at the world level by Olmi $(1984,1991)$ and more recently in the Oriental, Neotropical and Eastern Palaearctic regions by Xu et al. (2013), Olmi and Virla (2014) and Olmi and $\mathrm{Xu}(2015)$ respectively.

The species of Anteon inhabiting the Oriental region were studied by Xu et al. (2013). More recently, Guglielmino and Olmi (2013) and Olmi et al. (2015) described further new species respectively from Indonesia (Anteon seramense Guglielmino \& Olmi) and Thailand (Anteon huettingeri Olmi, Xu \& Guglielmino). In total, 150 Anteon species have been described from the Oriental region (Xu et al. 2013; Guglielmino and Olmi 2013; Olmi et al. 2015).

Anteon species are parasitoids of leafhoppers belonging to the Cicadellidae (Guglielmino et al. 2013). As in almost all dryinids, females of Anteon have a chelate protarsus. Chelae are used to capture and restrain the host during oviposition and hostfeeding (Olmi 1984, 1994).

In 2015 we examined additional specimens of Anteon from Laos and discovered a new species described in this paper.

\section{Material and methods}

The descriptions follow the terminology used by Olmi (1984) and Xu et al. (2013). The measurements reported are relative, except for the total length (head to abdominal tip, without antennae), which is expressed in millimetres. The following abbreviations are used in the descriptions: POL is the distance between the inner edges of the two lateral ocelli; OL is the distance between the inner edges of a lateral ocellus and the median ocellus; OOL is the distance from the outer edge of a lateral ocellus to the compound eye; OPL is the distance from the posterior edge of a lateral ocellus to the occipital carina; TL is the distance from the posterior edge of an eye to the occipital carina.

The types of all Oriental species of Anteon have been previously examined by the authors.

The type specimen described in this paper is deposited in the collection of the Oberösterreichisches Landesmuseum, Linz, Austria (OLL).

The description of the new species is based on the study of a single specimen. The authors are aware that descriptions of new taxa should normally be based on more individuals. However, Dryinidae are so rare that it is uncommon to collect more than one specimen of each species. In addition, on the basis of the experience and knowledge of the authors, the new species is sufficiently delimited by unique characters to justify its description. 


\section{Results}

\section{Genus Anteon Jurine, 1807}

Anteon Jurine, 1807: 302. Type species: Anteon jurineanum Latreille, 1809, by subsequent monotypy.

Diagnosis. Female: Fully winged; rarely brachypterous; occipital carina complete; palpal formula 6/3; antenna without rhinaria; forewing with three cells enclosed by pigmented veins (costal, median and submedian); forewing with stigmal vein and pterostigma; distal part of stigmal vein much shorter than proximal part, occasionally slightly shorter, as long as, or longer than proximal part; propodeum usually with transverse keel between dorsal and posterior surface; protarsus chelate; inner side of enlarged claw with proximal prominence bearing one long bristle; tibial spurs 1/1/2. Male: Fully winged; rarely brachypterous; occipital carina complete; vertex of head usually without two oblique keels connecting posterior ocelli to occipital carina; palpal formula 6/3; forewing with three cells enclosed by pigmented veins (costal, median and submedian); forewing with stigmal vein and pterostigma; distal part of stigmal vein much shorter than proximal part, occasionally slightly shorter, as long as, or longer than proximal part; pterostigma less than four times as long as broad; propodeum usually with transverse keel between dorsal and posterior surface; paramere usually without inner branch wrapping penis; tibial spurs 1/1/2.

\section{Anteon holzschubi Olmi, Xu, Guglielmino \& Speranza, sp. n.}

http://zoobank.org/80257611-458A-45B3-B633-292B862C17A3

Diagnosis. Male with antenna filiform; face partly reticulate rugose and partly sculptured by deep punctures similar to areolae (Fig. 1B); OOL about 3.3 times as long as OL (Fig. 1A); notauli reaching about 0.8 length of scutum (Fig. 1A); posterior surface of propodeum with two complete longitudinal keels and median area unsculptured; distal part of stigmal vein much shorter than proximal part; paramere about as long as penis, without papillae on inner side, without distal inner process (Fig. 2); distivolsella not provided with two lateral processes (Fig. 2).

Description. Male. Fully winged (Fig. 1A). Length $4.5 \mathrm{~mm}$. Head black, except mandible testaceous. Antenna brown-testaceous, except proximal half of segment 1 testaceous. Mesosoma black. Metasoma brown. Legs testaceous, except metacoxa basally brown. Antenna filiform. Antennal segments in following proportions: 17:10:16:15:14:14:14:14:13 (segment 10 missing in holotype). Head (Fig. 1A, B) shiny. Face partly rugose and partly strongly punctate, with deep punctures similar to areolae, unsculptured among punctures. Vertex and temple with deep punctures similar to areolae, unsculptured among punctures. Frontal line complete. Vertex with POL $=7 ; \mathrm{OL}=3 ; \mathrm{OOL}=10 ; \mathrm{OPL}=7 ; \mathrm{TL}=7$; greatest breadth of posterior ocelli shorter 


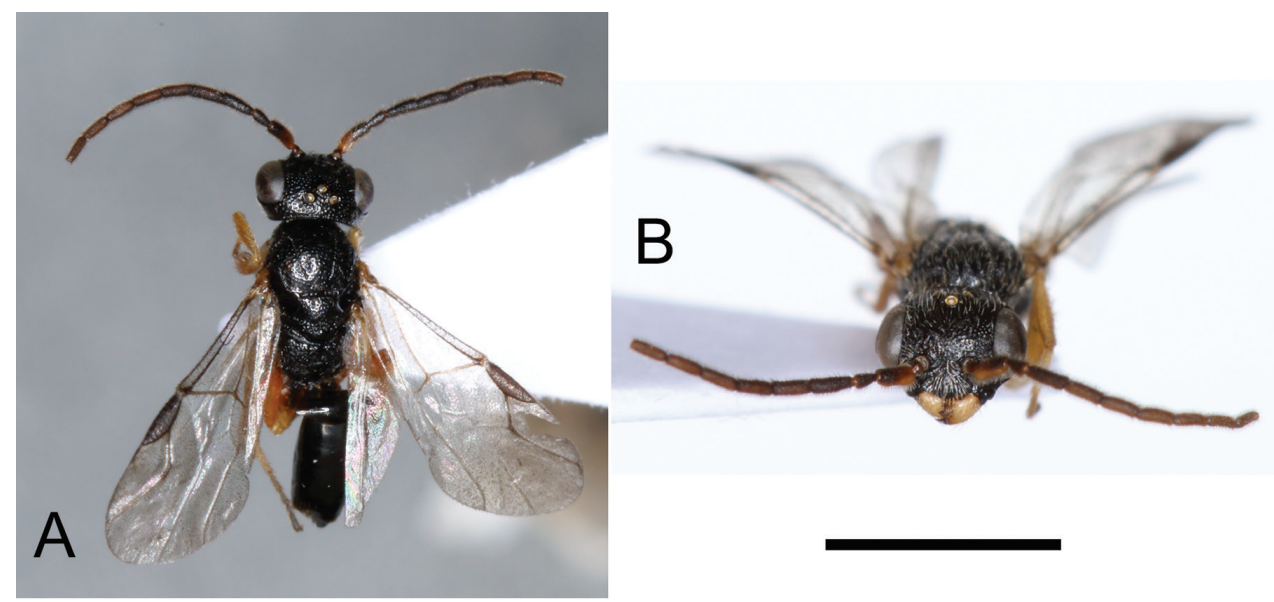

Figure I. Anteon holzschuhi Olmi, Xu, Guglielmino \& Speranza, sp. n., holotype: A habitus in dorsal view B head in frontal view. Scale bar: $2.77 \mathrm{~mm}(\mathbf{A}), 2.20 \mathrm{~mm}(\mathbf{B})$.

than OPL (5:7). Occipital carina complete. Pronotum short and strongly punctate. Scutum and scutellum shiny, punctate, unsculptured among punctures. Notauli incomplete, reaching approximately $0.8 \mathrm{x}$ length of scutum (Fig. 1A). Metanotum shiny, unsculptured. Propodeum with strong transverse keel between dorsal and posterior surface. Dorsal surface of propodeum reticulate rugose. Posterior surface of propodeum with two complete longitudinal keels, median area unsculptured, and lateral areas rugose. Forewing hyaline, without dark transverse bands. Distal part of stigmal vein much shorter than proximal part (7:16). Paramere (Fig. 2) about as long as penis, without distal inner pointed process and papillae, with long and broad dorsal proximal membranous process. Tibial spurs 1/1/2.

Female. Unknown.

Material examined. Holotype: male, Laos, Houaphanh Province, Phou Pan, Ort Ban Saleui environs, $20^{\circ} 13.30^{\prime} \mathrm{N} 103^{\circ} 59.26^{\prime} \mathrm{E}, 1350-1900$ m, 6-11.iv.2014, C. Holzschuh and locals leg. (OLL).

Distribution. Laos.

Hosts. Unknown.

Etymology. The species is named after the collector, Mr Carolus Holzschuh (Villach, Austria).

Remarks. The new species is similar to A. semipolitum Olmi, 2008, by having the antenna filiform, notauli reaching about $0.8 \times$ length of scutum (Fig. 1A), posterior surface of the propodeum with two complete longitudinal keels and unsculptured median area, distal part of stigmal vein much shorter than proximal part, paramere about as long as penis, without papillae on inner side, without distal inner process (Fig. 2) and distivolsella not provided with two lateral processes (Fig. 2). The main difference between the two species is in the facial sculpture (face partly reticulate rugose and partly sculptured by deep punctures similar to areolae in A. holzschuhi (Fig. 1B); face 


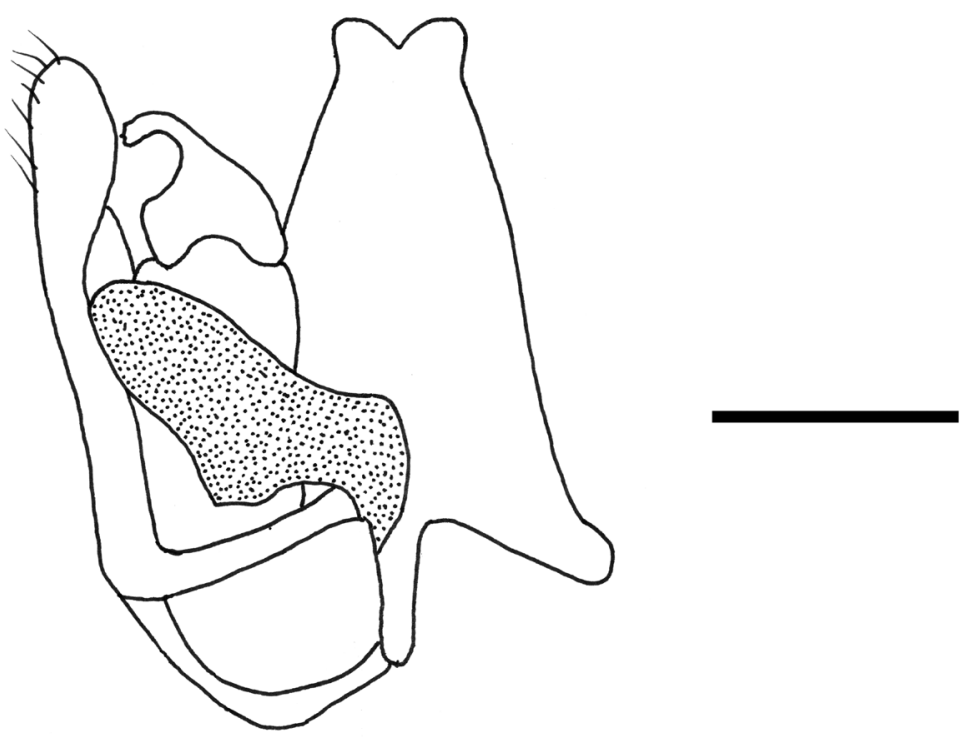

Figure 2. Anteon holzschuhi Olmi, Xu, Guglielmino \& Speranza, sp. n., holotype: male genitalia (right half removed). Scale bar $=0.26 \mathrm{~mm}$.

punctate and unsculptured among punctures in A. semipolitum). In addition, OOL is about three times as long as OL in $A$. holzschuhi, less than twice in A. semipolitum. In the key to the males of Oriental Anteon published by Xu et al. (2013), the new species can be included by replacing couplet 43 as follows:

$43 \quad$ Head partly or totally reticulate rugose (Fig. 1A, B) .................................43'

- $\quad$ Head completely punctate and unsculptured among punctures ..................44

43 Paramere with many papillae along inner side (Plate 38H in Xu et al. 2013)....

A. papillum Xu, He \& Olmi

- $\quad$ Paramere without papillae on inner side (Fig. 2; plate 42F in Xu et al.

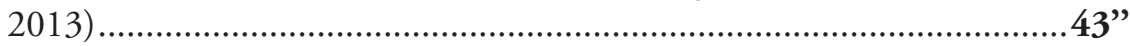

43" Face punctate and unsculptured among punctures; OOL less than twice as long as OL ................................................................... semipolitum Olmi

- $\quad$ Face partly reticulate rugose and partly sculptured by deep punctures similar to areolae (Fig. 1B); OOL about 3.3 times as long as OL (Fig. 1A)

A. holzschubi Olmi, Xu, Guglielmino \& Speranza, sp. n.

\section{Conclusion}

Mita and Okajima (2011), Xu et al. (2013) and Olmi et al. (2015) recorded from Laos 41 species of Dryinidae belonging to the following subfamilies and genera: Aphelopinae: Aphelopus Dalman, 1823 (five species); Anteoninae: Anteon Jurine, 1807 
(nine species), Deinodryinus Perkins, 1907 (one species); Bocchinae: Bocchus Ashmead, 1893 (four species); Dryininae: Dryinus Latreille, 1804 (16 species); Gonatopodinae: Neodryinus Perkins, 1905 (four species), Echthrodelphax Perkins, 1903 (two species). With the description of the above new species the number of species now known in Laos is 42. No hosts of Laotian Dryinidae are known.

In comparison with the 77 species listed in the Chinese province of Guangdong (total area: $177900 \mathrm{~km}^{2}$ ) (Xu et al. 2012c), the dryinid fauna of Laos (total area: $237800 \mathrm{~km}^{2}$ ) is poorly known. Some common genera such as Gonatopus Ljungh, 1810 (no species listed in Laos) are clearly understudied. Further evidence of this is the fact that on the small island of Hainan (total area: $33210 \mathrm{~km}^{2} ; 1 / 7$ that of Laos) 56 species of Dryinidae are recorded (Xu et al. 2011a, 2011c). In contrast, in the more northern Chinese provinces of Shaanxi (total area: $205800 \mathrm{~km}^{2}$ ) and Hunan (total area: 210000 $\mathrm{km}^{2}$ ) only 36 (Xu et al. 2012a) and 17 (Xu et al. 2011b, 2012b, 2013) dryinid species have been recorded, respectively.

\section{Acknowledgements}

Many thanks to Dr. Martin Schwarz (Oberösterreichisches Landesmuseum, Linz, Austria) for sending the specimen of Anteon described in the present paper. We are also grateful to all curators of collections who have sent us type material on loan. Many thanks to Dr. Robert C. Copeland (International Centre of Insect Physiology and Ecology (ICIPE), Nairobi, Kenya) for checking the English language of this paper. This paper was supported by the National Basic Research Program of China (No. 2013CB127600).

\section{References}

Ashmead WH (1893) Monograph of the North American Proctotrypidae. Bulletin of the United States National Museum 45: 1-472. doi: 10.5479/si.03629236.45.1

Carcupino M, Guglielmino A, Mazzini M, Olmi M (1998) Morphology and ultrastructure of the cephalic vesicles in two species of the Gonatopus genus: Gonatopus camelinus Kieffer and Gonatopus clavipes (Thunberg)(Hymenoptera, Dryinidae, Gonatopodinae). Invertebrate Reproduction and Development 34: 177-186. doi: 10.1080/07924259.1998.9652651

Dalman CR (1823) Analecta entomologica. Typis Lindhianis, Holmiae, Sweden, 104 pp. doi: 10.5962/bhl.title.66069

Guglielmino A, Bückle C (2003) Description of larval instars of Neodryinus typhlocybae (Ashmead, 1893) (Hymenoptera Dryinidae), with remarks on its biology. Mitteilungen aus dem Museum fuer Naturkunde in Berlin - Deutsche Entomologische Zeitschrift 50(1): 143-150. doi: 10.1002/mmnd.20030500114

Guglielmino A, Bückle C (2010) Description of larval instars of Mystrophorus formicaeformis Ruthe (Hymenoptera: Dryinidae). Zootaxa 2602: 57-66. 
Guglielmino A, Bückle C, Moya-Raygoza G (2006) Description of the larval instars of Gonatopus bartletti Olmi, 1984 (Hymenoptera: Dryinidae). Zootaxa 1226: 51-60.

Guglielmino A, Olmi M (2013) Description of Anteon seramense (Hymenoptera: Dryinidae), a new species from Indonesia. Florida Entomologist 96(2): 598-601. doi: 10.1653/024.096.0226

Guglielmino A, Olmi M, Bückle C (2013) An updated host-parasite catalogue of world Dryinidae (Hymenoptera: Chrysidoidea). Zootaxa 3740: 1-113. doi: 10.11646/zootaxa.3740.1.1

Guglielmino A, Parise G, Bückle C (2015) Description of larval instars of Dryinus tarraconensis Marshall, 1868 and Gonatopus baeticus (Ceballos, 1927) (Hymenoptera: Chrysidoidea: Dryinidae), parasitoids of the genus Dictyophara Germar (Hemiptera: Auchenorrhyncha: Dictyopharidae). Zootaxa 4032(1): 42-54. doi: 10.11646/zootaxa.4032.1.2

Guglielmino A, Virla EG (1998) Postembryonic development of Gonatopus lunatus Klug (Hymenoptera: Dryinidae: Gonatopodinae), with remarks on its biology. Annales de la Société entomologique de France (NS) 34(3): 321-333.

Jurine L (1807) Nouvelle méthode de classer les Hyménoptères et les Diptères, 1. Hyménoptères. Paschoud, Genève, Switzerland, 319 pp.

Latreille PA (1804) Nouvelle dictionnaire d'Histoire naturelle, 24. F. Dufart, Paris, 104 pp.

Ljungh SJ (1810) Gonatopus, novum insectorum genus. Beiträge zur Naturkunde 2: 161-163. Mita T, Okajima S (2011) Dryinus species collected from Laos (Hymenoptera, Dryinidae, Dryininae). Japanese Journal of Systematic Entomology 17(2): 153-154.

Olmi M (1984) A revision of the Dryinidae (Hymenoptera). Memoirs of the American Entomological Institute 37: 1-1913.

Olmi M (1991) Supplement to the revision of the world Dryinidae (Hymenoptera Chrysidoidea). Frustula Entomologica (NS) 12(25): 109-395.

Olmi M (1994) The Dryinidae and Embolemidae (Hymenoptera: Chrysidoidea) of Fennoscandia and Denmark (Fauna Entomologica Scandinavica 30). EJ Brill, Leiden, 100 pp.

Olmi M, Virla EG (2014) Dryinidae of the Neotropical Region (Hymenoptera: Chrysidoidea). Zootaxa 3792(1): 1-534. doi: 10.11646/zootaxa.3792.2.1

Olmi M, Xu Z (2015) Dryinidae of the Eastern Palaearctic region. Zootaxa 3996(1): 1-253. doi: 10.11646/zootaxa.3996.1.1

Olmi M, Xu Z, Guglielmino A (2015) A new species of the genus Anteon Jurine (Hymenoptera, Dryinidae) from Thailand. ZooKeys 504: 141-147. doi: 10.3897/zookeys.504.9333

Perkins RCL (1903) The leafhopper of the sugar cane. Territory of Hawaii, Board of Agriculture and Forest, Division of Entomology, Bulletin 1: 1-38. doi: 10.3897/zookeys.504.9333

Perkins RCL (1905) Leafhoppers and their natural enemies (Pt. i. Dryinidae). Report of Work of the Experiment Station of the Hawaiian Sugar Planters' Association, Division of Entomology, Bulletin 1(1): 1-69.

Perkins RCL (1907) Parasites of leaf-hoppers. Report of Work of the Experiment Station of the Hawaiian Sugar Planters' Association, Division of Entomology, Bulletin 4: 5-59.

Xu Z, Olmi M, Guglielmino A, Chen H (2011a) A new species of Dryinidae (Hymenoptera: Chrysidoidea) from China. Florida Entomologist 94(4): 848-852.

Xu Z, Olmi M, Guglielmino A, Chen H (2011b) Description of Aphelopus mangshanensis, a new species of Dryinidae from China. Bulletin of Insectology 64(2): 243-246. 
Xu Z, Olmi M, Guglielmino A, Chen H (2011c) Description of Anteon diaoluoshanense sp. nov. from China (Hymenoptera: Dryinidae). Pan-Pacific Entomologist 87(3): 172-176. doi: 10.3956/2011-31.1

Xu Z, Olmi M, Guglielmino A, Chen H (2012a) Checklist of Dryinidae (Hymenoptera: Chrysidoidea) from Shaanxi Province, China, with descriptions of two new species. Zootaxa 3164: 1-16.

Xu Z, Olmi M, Guglielmino A, Chen H (2012b) Descriptions of two new species of Anteon (Hymenoptera: Dryinidae) from China. Entomological News 121(5): 409-415.

Xu Z, Olmi M, Guglielmino A, Chen H (2012c) Checklist of Dryinidae (Hymenoptera) from Guangdong Province, China, with descriptions of two new species. Zootaxa 3231: 1-28.

Xu Z, Olmi M, He J (2013) Dryinidae of the Oriental region (Hymenoptera: Chrysidoidea). Zootaxa 3614: 1-460. doi: 10.11646/zootaxa.3900.1.1 